\title{
SPECTRUM OF BACTERIA IN NEONATAL SEPSIS AT THE DISTRICT HOSPITAL NICU ATTACHED TO MANDYA INSTITUTE OF MEDICAL SCIENCES, KARNATAKA
}

Keerthi A. M11, Keerthi B. J2, Mamatha P. S³, Anitha G4

\section{HOW TO CITE THIS ARTICLE:}

Keerthi A. M, Keerthi B. J, Mamatha P. S, Anitha G. "Spectrum of Bacteria in Neonatal Sepsis at the District Hospital NICU Attached to Mandya Institute of Medical Sciences, Karnataka". Journal of Evolution of Medical and Dental Sciences 2014; Vol. 3, Issue 45, September 18; Page: 11059-11063,

DOI: $10.14260 /$ jemds/2014/3443

ABSTRACT: INTRODUCTION: Neonatal sepsis is a clinical syndrome characterized by the systemic signs of infection and accompanied by bacteremia in the first month of life. In spite of great advances in antimicrobial therapy, neonatal life support measures and the early detection of risk factors, septicemia continues to be a major cause of mortality and morbidity among neonates around the world. Objective: To Review the bacterial pathogens of neonatal septicemia and their antibiotic sensitivity pattern. MATERIAL AND METHODS: The bacterial pathogens and their antimicrobial susceptibility test reports from 160 neonates clinically suspected of sepsis, admitted to Neonatal Intensive care Unit (NICU) of Mandya Institute of Medical Sciences (MIMS), over one year period (Jan 2010 to Dec 2010) was studied from the records of Microbiology Laboratory, MIMS. RESULTS: Out of 160 cases, 54(33.75\%) were positive in blood culture. Among the positive cases, Klebsiella species $20(37 \%)$ was the most frequent isolate followed by Staphylococcus aureus 11(20.3\%), E. Coli 6 (11.1\%), Coagulase Negative Staphylococcus 5(9.2\%), Pseudomonas aeruginosa 3(5.5\%), Acinetobacter species 2(3.7\%), Citrobacter 2(3.7\%) and Proteus mirabilis 2(3.7\%). Klebsiella species showed $100 \%$ resistance to ampicillin and $45 \%$ resistance to Amikacin. About $90 \%$ of Staphylococcus aureus showed resistance to penicillin and $100 \%$ of them were susceptible to Vancomycin. All Gram negative isolates were $100 \%$ susceptible to Imipenem and more than $77 \%$ were sensitive to Amikacin. CONCLUSION: Gram negative septicaemia was predominantly encountered with high resistance to first line drugs like Gentamincin and Ampicillin. Thus the initial therapy in our hospital may be aimed at Gram negative bacteria and Amikacin may be used as first drug of choice, while Imipenem is still the best for infection with multidrug resistant gram negative bacteria.

KEYWORDS: Neonatal septicaemia, Klebsiella species, Staphylococcus aureus, Antimicrobial resistance.

INTRODUCTION: Neonatal sepsis is a clinical syndrome characterized by systemic signs of infections and accompanied by bacteremia in the $1^{\text {st }}$ month of life. According to National Neonatal Perinatal Data (NNPF2002-03), incidence of neonatal sepsis is 30/1000 live births. ${ }^{1}$ Neonatal sepsis is an important cause of morbidity and mortality among neonates in India with an estimated incidence of approximately $4 \%$ in intramural live births. ${ }^{2}$

The microbial etiology of neonatal sepsis is variable and often changes temporarily. Groups B Streptococci is a common cause of neonatal sepsis in West but infrequent in India and other tropical countries. S aureus, Klebsiella, E. Coli along with CONS and Pseudomonas are the main organisms responsible for neonatal septicemia in India. ${ }^{3}$ 
Neonates are particularly vulnerable to infections because of weak immune barrier. Several risk factors have been identified both in neonates and mother who make them susceptible to infections. Also, the organisms isolated are often resistant to multiple antimicrobials which make the treatment difficult and grave sequel ensue. ${ }^{4}$

In view of the fulminating course of neonatal septicemia, every attempt should be made for early diagnosis and management. ${ }^{5}$ For effective management of neonatal septicemia with appropriate antibiotics to minimize risk of severe morbidity and mortality, besides reducing emergence of multidrug resistant organisms by rational antibiotic use, study of bacteriological profile and antibiotic sensitivity pattern play a significant role.6,7

The present study was carried out to review the spectrum of bacteria and their antibiotic sensitivity pattern in neonatal septicemia of our NICU to help the neonatologist for better empirical treatment of neonatal septicemia.

MATERIAL AND METHODS: Bacterial pathogens isolated from blood samples of 160 clinically suspected septicemia neonates admitted to District Hospital NICU, MIMS from Jan-Dec 2010, and their antimicrobial susceptibility test reports were reviewed from the Records of Microbiology Laboratory, MIMS.

RESULTS: Out of 160 clinically suspected cases studied, growth of bacteria was obtained in 54 (33.75\%) blood samples. Of these, Klebsiella species was the most frequent isolate (37\%) followed by S.aureus (20.3\%), E.coli (11.1\%), CONS (9.2\%) and other less frequent isolates (Table 1).

In Early onset sepsis (age $<1 w \mathrm{w}$ ), the most frequent isolate was Klebsiella species $(42.8 \%)$ followed by Staphylococcus aureus (21.4\%), E.coli (11.9\%) and others. In Late onset sepsis (LOS), CONS (33.3\%) was isolated most frequently followed by Klebsiella species (16.7\%) and Staphylococcus aureus (16.7\%) (Table.1).

\begin{tabular}{|c|c|c|c|}
\hline Bacteria isolates & Number (\%) & EOS (\%) & LOS (\%) \\
\hline Klebsiella species & $20(37.0)$ & $18(42.8)$ & $2(16.7)$ \\
\hline S.aureus & $11(20.3)$ & $09(21.4)$ & $2(16.7)$ \\
\hline E. Coli & $06(11.1)$ & $05(11.9)$ & $1(08.3)$ \\
\hline CONS & $05(09.2)$ & $01(02.3)$ & $4(33.3)$ \\
\hline Pseudomonas aeruginosa & $03(05.5)$ & $02(04.7)$ & $1(08.3)$ \\
\hline Acinetobacter species & $02(03.7)$ & $02(04.7)$ & $0(0)$ \\
\hline Citrobacter species & $02(03.7)$ & $02(04.7)$ & $0(0)$ \\
\hline Proteus mirabilis & $02(03.7)$ & $01(02.3)$ & $1(08.3)$ \\
\hline Proteus vulgaris & $01(01.8)$ & $01(02.3)$ & $0(0)$ \\
\hline Enterobacter species & $01(01.8)$ & $01(02.3)$ & $0(0)$ \\
\hline Enterococcus species & $01(01.8)$ & $00(0)$ & $1(08.3)$ \\
\hline Total & 54 & 42 & 12 \\
\hline
\end{tabular}

Table 1: Distribution of bacterial isolates from blood culture

EOS-Early onset septicemia

LOS-Late onset septicemia

CONS-Coagulase Negative Staphylococcus aureus. 
Antibacterial resistance pattern of Gram positive and Gram negative blood stream isolated are shown in Table 2 and Table 3, respectively.

\begin{tabular}{|l|c|c|c|c|c|c|c|c|c|}
\hline \multicolumn{1}{|c|}{ Organisms } & P & E & CO & V & Cp & G & T & Lz & Ox \\
\hline S. aureus n=11 & $10(80.9)$ & $6(54.5)$ & $6(54.5)$ & $0(0)$ & $5(45.4)$ & $4(36.3)$ & $5(45.4)$ & $0(0)$ & $9(81.8)$ \\
\hline CONS n=5 & $3(60)$ & $2(40)$ & $1(20)$ & $0(0)$ & $1(20)$ & $1(20)$ & $2(40)$ & $0(0)$ & $2(40)$ \\
\hline Enterococcus $n=1$ & $1(100)$ & - & - & $0(0)$ & - & 0 & $1(100)$ & - & - \\
\hline
\end{tabular}

Table 2: Antibacterial resistance pattern of Gram positive bacteria

Figures shown in table are number of resistant isolates.

Figures shown in parenthesis indicate percentage of resistant isolates.

$\mathrm{P}=$ Penicillin, $\mathrm{E}=$ Erythromycin, $\mathrm{Co}=$ Cotrimoxazole, $\mathrm{V}=$ Vancomycin, $\mathrm{Cp}=$ Ciprofloxacin. $\mathrm{G}=$ Gentamicin, $\mathrm{T}=$ Tetracycline, $\mathrm{Lz}=$ Linezolid, $\mathrm{Ox}=0 \mathrm{xacillin}$.

\begin{tabular}{|l|c|c|c|c|c|c|c|c|c|}
\hline \multicolumn{1}{|c|}{ Organisms } & Ap & Co & T & G & Ak & Cf & Cz & Cp & I \\
\hline Klebsiellasppn=20 & $20(100)$ & $12(60)$ & $13(65)$ & $15(75)$ & $9(45)$ & $14(70)$ & $11(55)$ & $13(65)$ & $0(0)$ \\
\hline E.colin=6 & $5(83.5)$ & $3(50)$ & $4(66.6)$ & $4(66.6)$ & $2(33.3)$ & $3(50)$ & $3(50)$ & $4(66.6)$ & $0(0)$ \\
\hline Pseudomonas aeruginosa n=3 & - & - & - & $2(66.6)$ & $1(33.3)$ & $2(66.6)$ & $1(33.3)$ & $2(66.6)$ & $0(0)$ \\
\hline Acinetobacter n=2 & - & $1(50)$ & - & $2(100)$ & $1(50)$ & $1(50)$ & $1(50)$ & $1(50)$ & $0(0)$ \\
\hline Citrobacter n=2 & $2(100)$ & $1(50)$ & $2(100)$ & $1(50)$ & $0(0)$ & $1(50)$ & $1(50)$ & $1(50)$ & $0(0)$ \\
\hline Proteus mirabills n=2 & $2(100)$ & $2(100)$ & $1(50)$ & $1(50)$ & $1(50)$ & $1(50)$ & $1(50)$ & $1(50)$ & $0(0)$ \\
\hline Proteus. Vulgaris n=1 & $1(100)$ & $1(100)$ & $1(100)$ & $0(0)$ & $0(0)$ & $0(0)$ & $0(0)$ & $1(100)$ & $0(0)$ \\
\hline Enterobacterspp n=1 & $1(100)$ & $1(100)$ & $1(100)$ & $1(100)$ & $0(0)$ & $0(0)$ & $0(0)$ & $0(0)$ & $0(0)$ \\
\hline
\end{tabular}

Table 3: Antibacterial resistance pattern of Gram negative bacteria

Figures shown in table are number of resistant isolates.

Figures shown in parenthesis indicate percentage of resistant isolates.

$\mathrm{Ap}=$ Ampicilin, $\mathrm{Co}=$ Cotrimoxazole, $\mathrm{T}=$ Tetracycline, $\mathrm{G}=\mathrm{Gentamicin}$.

$\mathrm{Ak}=$ Amikacin, $\mathrm{Cf}=$ Cefotaxime, $\mathrm{Cz}=$ Ceftazidime, $\mathrm{Cp}=$ Ciprofloxacin, $\mathrm{I}=$ Imipenem.

DISCUSSION: In the present study, it was observed that culture positive neonatal septicemia was seen in $33.75 \%$ cases. This incidence closely matches with some Indian studies, $40 \%{ }^{3}, 24 \%{ }^{8}$, and $27 \%,{ }^{5}$ and as well studies abroad $30 \% .^{9}$

The weaker immune system in neonates and children explains this higher rate of isolation. In our study, out of 54 bacterial isolates, majority were Gram negative bacilli 37 (6805\%). Klebsiella species was isolated most frequently in 20(47\%) cases followed by S. aureus 11(20.3\%), E. coli 6 (11.1\%), CONS 5 (9.2\%), Pseudomonas aeruginosa 3(5.5\%), Acinetobacter species 2 (3.7\%), Citrobacter species 2 (3.7\%), Proteus mirabilis 2 (3.7\%), Proteus vulgaris, Enterobacter species and Enterococcus 1 each (1.8\% each).

Klebsiella species was a predominant isolate in other Indian studies.9,10,4 Staphylococcus aureus was the predominant isolate in some studies abroad.11,12 Area based knowledge of bacteriological spectrum is essential for empirical therapy. An incidence of $9.2 \%$ for CONS was seen in our study.

CONS is usually regarded as a skin contaminant, but Leon et.al ${ }^{13}$ opined that his bacterium in the blood could no longer be taken as contaminant especially in patients in critical care units.

In Early onset sepsis (EOS), Klebsiella species was the most frequent offender in 18 (42.8\%) cases, followed by S. aureus $9(21.4 \%)$ and others. CONS $4(33.3 \%)$ was the most frequently isolated 
pathogen from Late onset sepsis (LOS). This is in accordance with other Indian studies ${ }^{14,15}$. Incidence of Acinetobacter septicaem in our study was 3.7\% which is slightly lower than that reported by Vinod Kumar and Neelagund (8.3\%). ${ }^{16}$ However, Acinetobacter species are fast emerging as important nosocomial pathogens as evidenced by other Indian studies. ${ }^{16,17}$

Klebsiella species which was the most frequent isolate showed $100 \%$ resistance to ampicillin, $75 \%$ to gentamicin and least resistance to amikacin (45\%). All other isolates were sensitive to imipenem. Klebsiella is a major agent of neonatal nosocomial infections. It continues to be a nightmare for neonatologists, microbiologists and hospital administrators.

Multidrug resistant Klebsiella pneumonia species was the commonest organism isolated by A Malik etal. ${ }^{18}$ Acinetobacter species isolated in our study also showed multidrug resistance with $100 \%$ resistance to Gentamicin. About $90 \%$ of S. aureus and $60 \%$ of CONS were found resistant of penicillin. All were sensitive to Vancomycin and Linezolid. MSRA was noted in $81.8 \%$ of S. aureus isolates.

CONCLUSION: The high frequency of resistance to Beta lactum antibiotics may be due to their indiscriminate use as first line drugs. Amikacin is a good alternative to which most Gram negative isolates were found susceptible in our study, and while Imipenem is still the best, for infections with multidrug resistant gram negative bacteria.

\section{REFERENCES:}

1. National Neonatology Forum of India National Perinatal Database-report for year 2002-2003, New Delhi, NNF, India-2004.

2. Neonatal morbidity and mortality: report of the National-Neonatal-Perinatal Database. Indian Pediatr 1997; 34:1039-42.

3. Sugandhi Rao P, Meena Baliga, Shivananda PG. Bacteria of Neonatal septicemia in a rural referral hospital in South India, J Trop Paediatrics 1993; 39 (4): 230-3.

4. Roy I, Jain A, Kumar M, Agarwal SK GB acteriology of Neonatal Septicaemia in a tertiary care hospital of Northern India. Ind J Med Microbiology, 2002; 20 (3): 156-9.

5. Neeraj Kumar Jain, Deepak Seth, Vibha Mangal, A Clinicomicrobial association in neonatal septicaemia Ind J Pedia OCT 2010.

6. Edwards MS. Postnatal infections. Inn Neonatal-Perinatal Medicine. Edited by Fanaroff, Martins, $8^{\text {th }}$ ed. Philadelphia, Mosby Elsevier 2006; 791-804.

7. Chacko B, Sohi J. Early onset neonatal sepsis. Indian J Pedia 2005; 72: 23-6.

8. Mathur M, Shah H, Dixit K. Khamnodkone S, Chakrapani A, Irani S. Bacterial profile of neonatal septicaemia cases(for the year 1990-91) J. Postgrad Med 1994 Jan-Mar: 40 (1) 18-20.

9. Das PK, Basu K, Chakraborty P, Bhownik PK. Clinical and bacteriological profile of neonatal infection in metropolitan city based medical college nursery. I Ind Med Association 1999: 97: 3-5.

10. Kapoor H, Sumanthi N, Agarawal P, Jain SD, Kur J. Spectrum of bacterial isolates in high risk areas of a tertiary care hospital: 3 years study. Ind J Me Microbiology 2000: 18: 166-9.

11. Mokululu AO, Jiya N, Aderiyan 0 O. Neonatal septicaemia in llorin: bacterial pathogens and antibiotic sensitivity pattern. Afr J Med Sci 2002 Jan, 31 (2): 127-30.

12. Ako - Nai A K, Adejujbe E A, Ajayi F M, Onipede A O. The Bacteriology of Neonatal septicaemia in Ile Ife, Nigeria. J Trop Peaed 1999: 45: 146-51. 


\section{ORIGINAL ARTICLE}

13. Pence de leon S, Wenzel P P. Hospital acquired Blood Stream infections with Streptococcus epi9dermidis. Review of 100 cases, Am J Med 1984; 77; 639-44.

14. Sanghvi KP and Tudehope DI. Neonatal bacterial sepsis in a NICU: A 5 year analysis. J Pediatr Child Health 1996; 32: 333-8.

15. Mane Ak, Nagdeo NV, Thombare VR. Study of neonatal septicaemia in a tertiary care hospital in rural Nagpur, J Recent advances in Applied Sciences 2010; 25: 19-24.

16. Vinod Kumar CS, Neelagund YF. Acinetobactersepticaemia in neonates. I J Med Microbiology 2004; 22 (1): 71.

17. Arora U, Jaitwani J. Acinetobacterspp - Emerging pathogen in neonatal Septicaemia in Amritsar. I J Med Microbiology 2006; 24 (1): 81.

18. Malik A, Hasani AW, Shahid M, Khan HM, Ahamed AJ. Nosocomial Klebsiella infection in neonates in a tertiary care hospital, protein profile by SDS-PAGE and klebosin typing as epidemiological markers I J Med microbiology 2003; 221 (2): 82-6.

\section{AUTHORS:}

1. Keerthi A. M.

2. Keerthi B. J.

3. Mamatha P. S.

4. Anitha G.

\section{PARTICULARS OF CONTRIBUTORS:}

1. Associate Professor, Department of Microbiology, Mandya Institute of Medical Sciences (MIMS), Mandya, Karnataka.

2. Assistant Professor, Department of Paediatrics, Mandya Institute of Medical Sciences (MIMS), Mandya, Karnataka.

3. Assistant Professor, Department of Microbiology, Mandya Institute of Medical Sciences (MIMS), Mandya, Karnataka.
4. Junior Resident, Department of Paediatrics, Mandya Institute of Medical Sciences (MIMS), Mandya, Karnataka.

\section{NAME ADDRESS EMAIL ID OF THE CORRESPONDING AUTHOR:}

Dr. Keerthi B. J,

Assistant Professor,

Department of Pediatrics, MIMS, Mandya.

Email: drkeerthibj28@gmail.com

Date of Submission: 25/08/2014.

Date of Peer Review: 26/08/2014.

Date of Acceptance: 10/09/2014.

Date of Publishing: 18/09/2014. 